\title{
CHANGES OF CHOLINESTERASE ACTIVITY IN THE ERYTHROCYTES, PLASMA, DIAPHRAGM, LIVER AND VARIOUS PARTS OF THE BRAIN IN THE RABBIT FOLLOWING TRANSFUSION OF ERYTHROCYTES WITH SOMAN INHIBITED ACETYLCHOLINESTERASE
}

\author{
Jiři Kassa, Jiři Bajgar and Josef Fusek \\ Purkyně Military Medical Academy, Hradec Králové; (Head: doc. MUDr. S. Býma, CSc.)
}

\begin{abstract}
Summary: 1 . The changes of cholinesterase activity in rabbit blood, peripheral tissues and the central nervous system following transfusion of erythrocytes with soman inhibited acetylcholinesterase we- were demonstrated. 2. After incubation with soman for 0.5 or $24 \mathrm{~h}$, erythrocytes without acetylcholinesterase activity were injected to intact rabbits and cholinesterase activity in the erythrocytes, plasma, diaphragm, liver and various parts of the brain were evaluated $24 \mathrm{~h}$ following blood-transfusion. 3. When erythrocytes were incubated with soman for $24 \mathrm{~h}$, no changes of cholinesterase activity in the rabbit following blood-transfusion were observed with an exception of erythrocyte acetylcholinesterase. 4 . When erythrocytes were incubated with soman for $0.5 \mathrm{~h}$, a significant decrease in cholinesterase activity in the erythrocytes, plasma, diaphragm and liver following blood-transfusion was found. These data show that soman is able to release from erythrocytes and inhibit cholinesterase activities not only in vitro but also in vivo although the significant inhibition of cholinesterase activities by soman was only observed in the peripheral compartment.
\end{abstract}

Key words: Soman; Acetycholinesterase; Butyrylcholinesterase; Blood-transfusion; Rabbit

\section{Introduction}

In spite of a good knowledge of the basic mechanism of nerve agent toxic effects, the treatment of acute intoxication with nerve agents has not been satisfactorily efficacious yet (3). Especially soman (pinacolyl methylphosphonofluoridate) is really resistant to antidotal treatment $(7,8,10)$. Soman differs from many other organophosphates in the rate of aging and in the existence of a depot in the organism (2). The rapid process of aging, that means the monodealkylation of soman-inhibited acetylcholinesterase (AChE, EC 3.1.1.7), prevents both the spontaneous reactivation and the reactivation induced by oximes $(2,5)$. The existence of a soman depot in the organism can also influence soman poisoning because soman can be released from the depot and cause a new attack of intoxication. This depot was described for the skin, muscles and lung $(2,6)$.

Another structure, where soman could be released from, is the erythrocyte. In experiments in vitro, the ability of soman to release from erythrocytes after inbubation with them was found. This ability was evaluated with the help of incubation of soman-intoxicated erythrocytes with horse plasma butyrylcholinesterase (BuChE, EC 3.1.1.8). The soman ability to release from erythrocytes depends on the time of soman incubation with them. The amount of released soman decreases if the time of erythrocyte incubation with soman increases (1).
The ability of soman to release from erythrocytes could be important for acute soman intoxication because a considerable part of soman could be transported to the site of its toxic effect after its binding on erythrocytes and could reinhibit oxime-reactivated $\mathrm{AChE}$ in the peripheral or central compartment.

The aim of this study was to demonstrate the changes of AChE or BuChE activity in the peripheral and central compartments following blood-transfusion of rabbits with soman-incubated erythrocytes.

\section{Methods}

Male rabbits $(3.4$ - 3.7kg) obtained from Konárovice were kept in the animal house at the Department of Toxicology of the Military Medical Academy. The animals were allowed free access to standard laboratory food and tap water. They were housed in an air-conditioned room (20-22 $\left.{ }^{\circ} \mathrm{C}\right)$ on 12 -h light/12-h dark cycles. Handling of experimental animals was made under the supervision of the Ethics Commitee of Medical Faculty of Charles University and Military Medical Academy.

After exsanguination of the anaesthetized rabbit (urethan i.p. $1 \mathrm{~g} / \mathrm{kg}$ ), the blood was centrifuged to obtain erythrocytes and plasma. Erythrocytes were incubated with soman $\left(10^{-3} \mathrm{M}\right)$ for 0.5 or $24 \mathrm{~h}$. Following the incubation and separation of erythrocytes from soman solution by 
centrifugation, erythrocytes were washed with saline solution three times.

These erythrocytes were added into rabbit plasma and exchanged blood-transfusion to another rabbit was performed $(30 \mathrm{ml} / \mathrm{kg})$. The number of animals was six in the control (blood-transfusion with erythrocytes without incubation with soman) as well as experimental groups. The experiments were terminated $24 \mathrm{~h}$ after blood-transfusion. Each rabbit was killed by air embolism into the carotid artery; blood, diaphragm, liver and brain were removed and the brain was divided into parts. Hemispheres, cerebellum, medulla oblongata and pons Varoli were chosen for the experiments. The blood was centrifuged to obtain erythrocytes and plasma. The erythrocytes were hemolysed and the diaphragm, liver and brain parts were homogenized in distilled water. The AChE and BuChE activity were measured by a spectrophotometric assay using acetylthiocholine or butyrylthiocholine as the substrates (4).

The total AChE or BuChE activities were expressed as $\mu \mathrm{mol}$ substrate hydrolyzed $/ \mathrm{ml} / \mathrm{min}$ and presented as percents of controls. Statistical significance was determined by the use of Student $t$ test and differences were considered significant when $p<0.05$. Statistical evaluation was performed with relevant programmes using an ADT 4500 computer.

\section{Results}

The changes of AChE or BuChE activities in the erythrocytes, plasma, diaphragm, liver and various parts of the brain following blood-transfusion with erythrocytes incubated with soman for $24 \mathrm{~h}$ are shown in Fig. 1. Only the erythrocyte AChE activity significantly decreased $(p<0.05)$ in comparison with control rabbits because the erythrocytes without AChE activity were injected into rabbits. The BuChE activity in the plasma and liver as well as the $\mathrm{AChE}$ activity in the diaphragm and brain parts tested were not significantly changed in comparison with controls.

The changes of AChE or BuChE activities in the erythrocytes, plasma, liver, diaphragm and various parts of the brain following blood-transfusion with erythrocytes incubated with soman for half an hour are shown in Fig. 2. Not only the erythrocyte AChE activity but also the diaphragm AChE activity as well as the plasma and liver BuChE activity were significantly decreased in comparison with control rabbits $(\mathrm{p}<0.05)$. On the other hand, the $\mathrm{AChE}$ activity in various parts of the brain was not significantly different from the control AChE activity values.

\section{Discussion}

Antidotal treatment that consists of anticholinergic drugs to counteract the accumulation of acetylcholine and oximes to reactivate the nerve agent inhibited $\operatorname{AChE}(3,9)$ is not sufficiently effective against acute soman intoxication because of rapid aging and depot existence $(2,7,8,10)$. To improve the efficacy of antidotal treatment of acute intoxi-

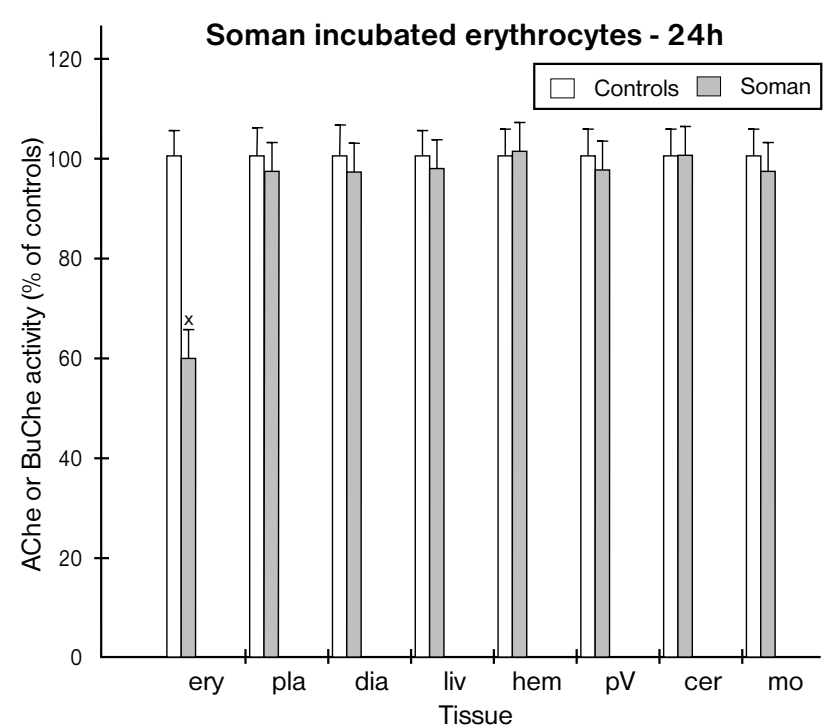

Fig. 1: Changes of AChE activity in the erythrocytes (ery), diaphragm (dia) and various parts of the brain (hem, $\mathrm{pV}$, cer, mo) and the BuChE activity in the plasma (pla) and liver (liv) following blood-transfusion with erythrocytes incubated with soman for $24 \mathrm{~h}$ in rabbits.

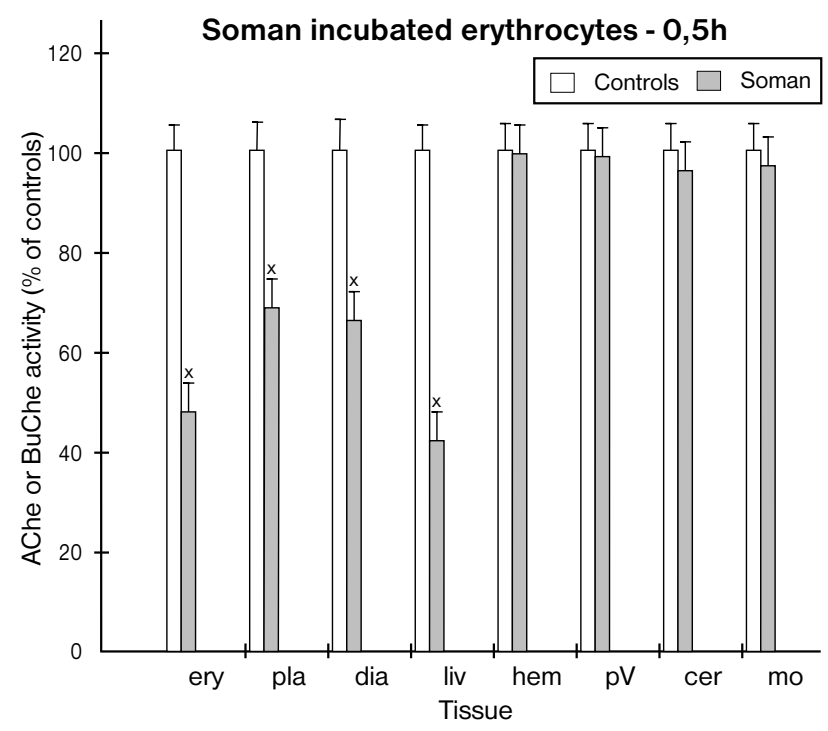

Fig. 2: Changes of AChE activity in the erythrocytes (ery), diaphragm (dia) and various parts of the brain (hem, pV, cer, mo) and the BuChE activity in the plasma (pla) and liver (liv) following blood-transfusion with erythrocytes incubated with soman for $0.5 \mathrm{~h}$ in rabbits.

cation with soman, it is necessary to better understand the toxikinetics as well as toxidynamics of soman intoxication (2).

Our results confirm that soman is able to release from erythrocytes after binding on them. The rate of soman releasing depends on the time of the incubation of erythrocy- 
tes with soman. Following $24 \mathrm{~h}$ incubation, soman released in a concentration of $2.62 \cdot 10^{-10} \mathrm{M}(1)$ and it was not able to inhibit the AChE activity in vitro and in vivo after bloodtransfusion of the rabbits with soman-incubated erythrocytes. Following $0.5 \mathrm{~h}$ incubation, soman released in a concentration of $4.64 \cdot 10^{-8} \mathrm{M}(1)$ and it was able to inhibit the $\mathrm{AChE}$ or $\mathrm{BuChE}$ activities not only in vitro but also in vivo after blood-transfusion of the rabbits with soman-incubated erythrocytes.

The significant decrease in the cholinesterase activities was demonstrated in the peripheral compartment (plasma, diaphragm, liver) but not in the central compartment (various parts of brain). It is very difficult to explain this fact. We suppose that the features of soman can be changed following its releasing from erythrocytes and that is why it is not able to across the blood-brain barrier. The further research with labeled soman could be useful for the confirmation of our hypothesis.

In conclusion, not only the skin, muscles or lung but also erythrocytes could be depot for soman and soman releasing from erythrocytes could contribute to the development of acute soman intoxication.

\section{Acknowledgement}

The authors express their appreciation to Mrs. R. Věříšová and M. Zechovská for their technical assistance and to Mr. V. Bláha for his help with statistical evaluation.

\section{References}

1. Bajgar J, Kassa J, Krs O, Fusek J. Inhibition of rabbit erythrocyte acetylcholinesterase by soman (lecture). The Fifth International Symposium on Protection against Chemical and Biological Warfare Agents, June 11-16, 1995, Stockholm Sweden.
2. Bajgar J. Present views on toxidynamics of soman poisoning. Acta Med (Hradec Králové), 1996;39:101-5.

3. Dawson RM. Review of oximes available for treatment of nerve agent poisoning. J Appl Toxicol 1994;14:317-31.

4. Ellman GL, Courtney DK, Andres JrV, Featherstone RN. A new and rapid colorimetric determination of acetylcholinesterase activity. Biochem Pharmacol 1961;7:88-95.

5. Fleisher JH, Harris LW. Dealkylation as a mechanism for aging of cholinesterase after poisoning with pinacolyl methylphosphonofluoridate. Biochem Pharmacol 1965; 14:641-8.

6. Kadar T, Raveh L, Cohen $\mathrm{G}$ et al. Distribution of $\mathrm{H}^{3} \mathrm{H}$ soman in mice. Arch Toxicol 1985;58:45-9.

7. Kassa J. Comparison of efficacy of two oximes (HI-6 and obidoxime) in soman poisoning in rats. Toxicology 1995; 101:167-74.

8. Koplovitz I, Stewart JR. A comparison of the efficacy of HI-6 and 2-PAM against soman, tabun, sarin and VX in the rabbit. Toxicol Lett 1994;70:269-79.

9. Marrs TC. Organophoshate poisoning. Pharmacol Ther 1993;58:51- 66 .

10. Shih T-M. Comparison of several oximes on reactivation of soman - inhibited blood, brain and tissue cholinesterase activity in rats. Arch Toxicol 1993;67:637-46.

This study was supported by the grant of IGA MZ No 4074-2.

Submitted May 1997.

Accepted June 1997.

Doc. MUDr. Jiří Kassa, CSc., Purkyně Military Medical Adademy, 50001 Hradec Králové, Czech Republic. 